\title{
A Comparison of Macroscopic Fracture Surface and Crack Growth Rate of Ti-6Al-4V
}

\author{
Kh. Farhangdoost ${ }^{a}$, S. Rahnama ${ }^{b}$ \\ Department of Mechanical Engineering, Ferdowsi University of Mashhad, Iran \\ afarhang@um.ac.ir, bsa_ra42@stu-mail.um.ac.ir
}

Keywords: Titanium, Microstructure, Fracture surface, Transition region,

\begin{abstract}
A comparison between crack growth rate $(\mathrm{da} / \mathrm{dN})$ vs. effective stress intensity range factor $\left(\Delta \mathrm{K}_{\mathrm{eff}}\right)$ curve behavior and microscopic and macroscopic fracture surface of commercial Ti$6 \mathrm{Al}-4 \mathrm{~V}$ alloy are presented. Three different regimes are correlated with characteristics measured on the fracture surfaces. Three regions can be observed in which part $I$ is rough and darker than others parts known as pre-transition, part II is smooth and light known as transition region and part III is a little darker than part II known as post-transition region. In the present investigation the correlation of fatigue crack growth rate for Ti-6Al-4V and microstructure of fracture surface has been presented.
\end{abstract}

\section{Introduction}

Two-phase $\alpha+\beta$ titanium alloys are used in a wide variety of aerospace applications (e.g. turbineengines in commercial and military aircrafts) because they exhibit excellent fatigue crack propagation resistance, fracture toughness, creep resistance and low density [1]. It is used in a variety of micro structural conditions, depending on the properties desired. The bimodal microstructure is produced by deformation in the $\alpha+\beta$ region with subsequent recrystallization and ageing to produce a microstructure consisting of equiaxed $\alpha$ grains and transformed $\beta$ grains containing $\alpha$ laths. The $\beta$-aged microstructure consists of a lath in a $\beta$-matrix. Previous studies have suggested that the fatigue behavior and mechanical properties of $\alpha+\beta$ titanium alloys are greatly influenced by their microstructures. Chan et al. [2] studied the deformation behavior of individual colony of $\alpha+\beta$ titanium alloy in compression and found that the yield stress of a colony varied with the angle between the primary slip system and the colony orientation. Further, several studies suggested that fatigue crack growth behavior was affected by the microstructure (colony size and orientation) [3-7]. The forementioned and several other studies have shown that the microstructure considerably influences fatigue crack growth behavior [8]. Low cycle fatigue (LCF) tests at stress ratios $(\mathrm{R})$ of 0 and -1 showed a significant dependence of fatigue life on grain morphology $[9,10]$. Many of these researches have an overall view on microstructure affect on fatigue crack growth rate with no attention local view of microstructure affect on crack growth path.

Microstructure of the fracture surface characteristics has the capability to identify fatigue crack growth rate behavior in Paris regime. In the present investigation the relationship of fatigue crack growth rate for Ti-6Al-4V and microstructure of fracture surface has been presented.

\section{Material and experimental procedure}

Material. The material used in the present study was Ti-6Al-4V forged plates, which had been preheated and solution treated at $935{ }^{\circ} \mathrm{C}$ for $105 \mathrm{~min}$, cooled under flowing air, vacuum annealed at $705{ }^{\circ} \mathrm{C}$ for $2 \mathrm{~h}$, and then cooled under flowing argon. This resulted in a duplex microstructure consisting of approximately $60 \%$ (volume) of nearly equiaxed primary $\alpha$ (hcp) and $40 \%$ (volume) of transformed $\beta$ (lamellar $\alpha+\beta$ colonies consisting of $\alpha$ platelets in a $\beta$ matrix-bcc) phases with a grain size of about $10 \mu \mathrm{m}$. This microstructure has been referred to as solution treated and averaged as 
well as bimodal [11]. The shape of this microstructure is shown in Fig.1; the composition of the material is given in table 1 and table 2 specifies mechanical properties of Ti-6Al-4V forged plates.

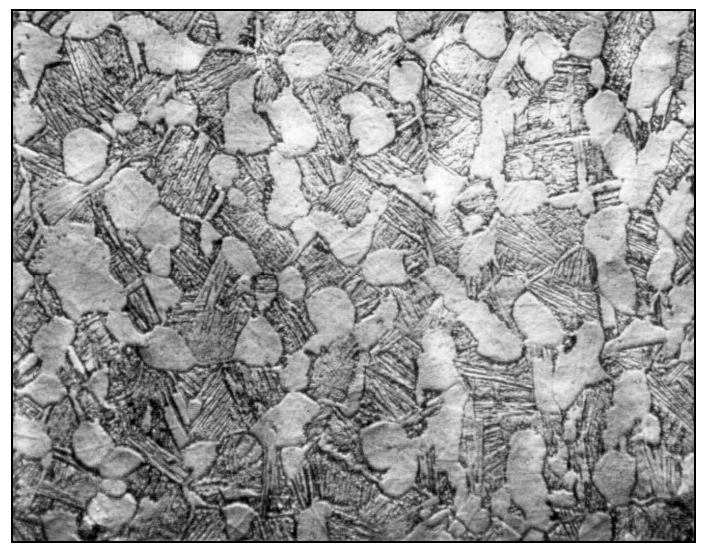

Fig.1. Microstructures used in the study; duplex with primary $\alpha$ and acicular $\alpha+\beta$

Table2. Room temperature material properties of Ti-6Al-4V forged plate

\begin{tabular}{cccccc}
\hline $\begin{array}{c}\text { Forged } \\
\text { Ti-6Al-4V }\end{array}$ & $\sigma_{\mathrm{y}}[\mathrm{MPa}]$ & UTS $[\mathrm{MPa}]$ & $\mathrm{E}[\mathrm{MPa}]$ & Elongation $[\%]$ & $\begin{array}{c}\text { Fracture toughness } \\
{\left[\mathrm{MPa} . \mathrm{m}^{1 / 2}\right]}\end{array}$ \\
\hline Fan disc & 856 & 949 & 117000 & 11 & 53.7 \\
\hline
\end{tabular}

Fractography. At the end of each test, all specimens were sectioned longitudinally. Both crack surface and fatigue crack growth path in Paris regime were observed through SEM and optical microscope. The surface of the crack propagation path was etched before observation to clearly illustrate the growing path and microstructures.

\section{Results and discussion}

The key observation was the change in the growth rate, which occurred in almost every test, indicating that fatigue crack propagation is not a stable, smooth, well ordered process. The key observation in Fig. 3 was the change of the fatigue crack growth rates show two transition points, namely at $\Delta \mathrm{K}_{\text {eff }}=8$ $\mathrm{MPa} \cdot \mathrm{m}^{1 / 2}$ and at $\Delta \mathrm{K}_{\mathrm{eff}}=12 \mathrm{MPa} \cdot \mathrm{m}^{1 / 2}$. These transition points follow macroscopically visible changes in fatigue crack surfaces, an example of which is shown in Fig.2. Three regions can be observed in which part I is rough and darker than others parts known as pre-transition, part II is smooth and light known as transition region and part III is a little darker than part II known as post-transition region. These region are related to crack growth rate vs. $\Delta \mathrm{K}_{\text {eff }}$ curve behavior which shown in Fig.3.

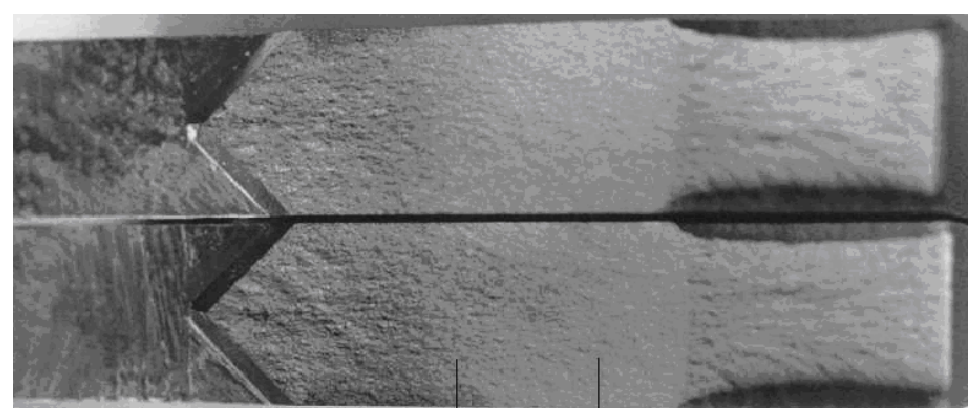

Fig.2. Visual fracture surface of C(T) specimens of Ti-6Al-4V. 


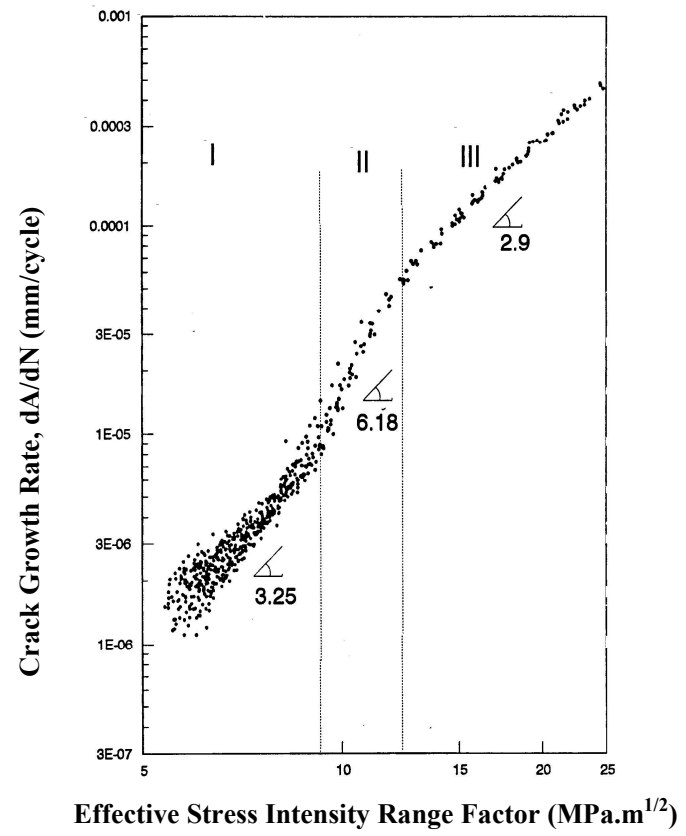

Fig.3. Fatigue crack growth rate vs. effective stress range

Furthermore, the corresponding microscopic views of these regions are shown in Figs.4 (a-f). Figs.4 (a) and (b) show the characteristic feature of pre-transition region it consist of cyclic cleavage facets and a complex mixture of structure sensitive fractures and striation spacing in some smooth region. Figs.4 (c) and (d) show transition region it consist of rough cyclic cleavage associated with micro cracks or rough cyclic cleavage and striation spacing. The reason of occurrence of this phenomena may be related to the observation that it is concluded the fatigue crack growth curve transition most probably occurred as a consequence of the maximum extent of the cyclic plastic zone becoming equal to and exceeding the average platelet $\alpha$ size. Fig.4 (e) and (f) show a representative view of immediately post-transition fatigue fracture, that those consist of smooth and irregular continuum mode fracture more striation spacing.

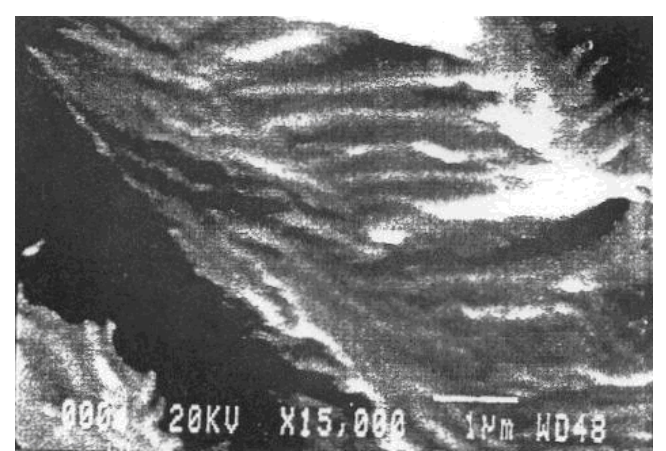

(a)

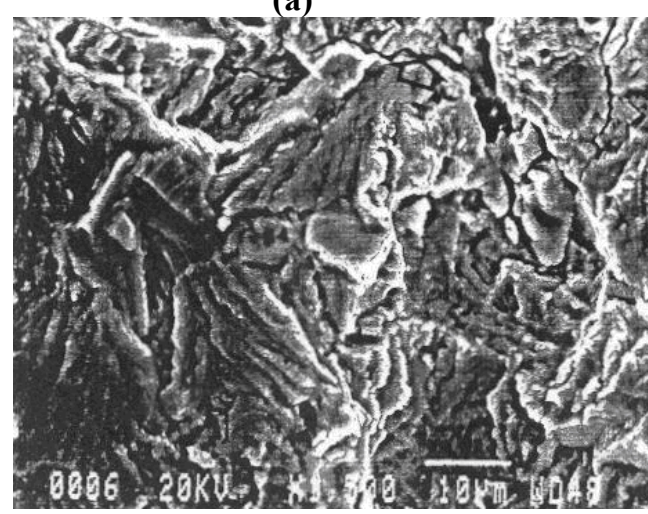

(c)

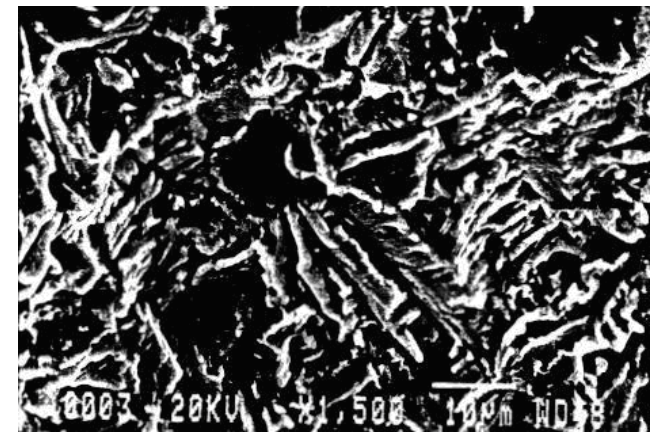

(b)

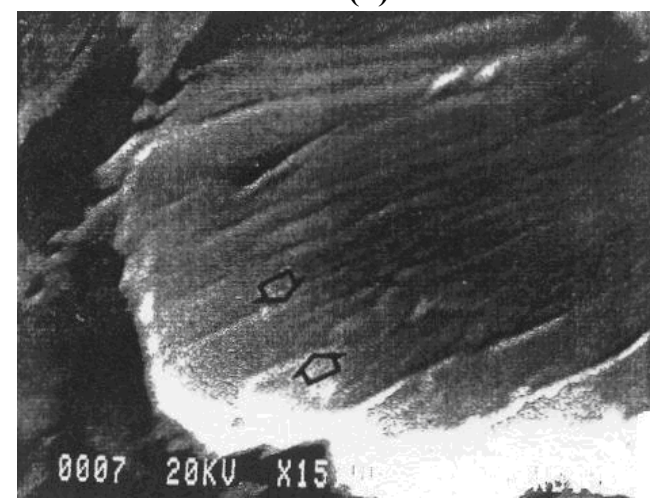

(d) 


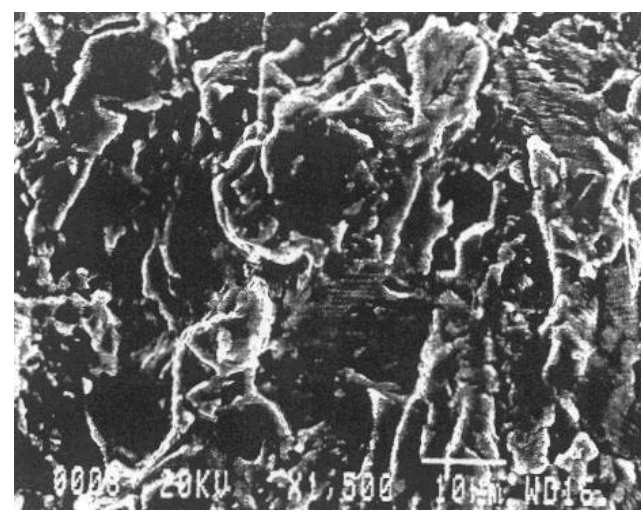

(e)

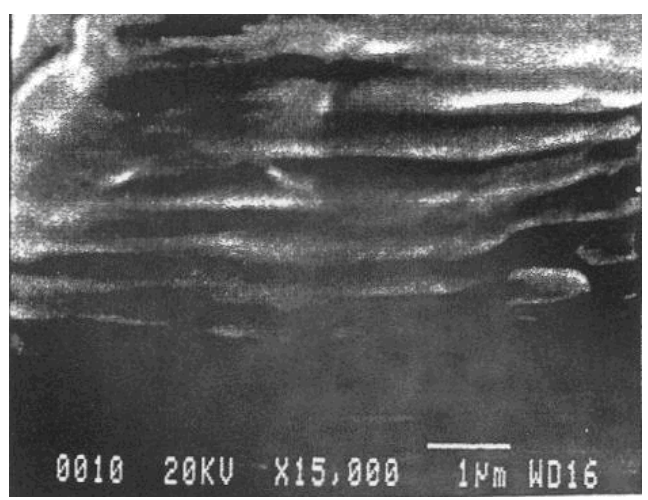

(f)

Fig.4. Microscopic view of transition regions[X15000]; (a) Characteristic feature of pre-transition; (b) Striation spacing of pre-transition; (c)Characteristic feature of transition; (d) Striation spacing of transition; (e) Characteristic feature of post-transition; (f) Striation spacing of post-transition.

\section{References}

[1] G.R. Yoder, D. Eylon: Metall. Mater. Trans. A. Vol. 10 (1979), p. 1808.

[2] K.S. Chan, C.C. Wojcik, D.A. Koss: Metall. Mater. Trans. A. Vol. 12 (1981), p. 1899.

[3] K.S. Ravichandran: Acta Metall. Mater. Vol. 39 (1991), p. 401.

[4] P. Lehr, in: H. Kimura, O. Izumi (Eds.), Titanium'80 Science and Technology, Metallurgical Society of AIME, Warrendale, PA. (1980), p. 1617.

[5] M. Peters, A. Gysler, G. Luetjering, in: H. Kimura, O. Izumi (Eds.), Titanium'80 Science and Technology, Metallurgical Society of AIME, Warrendale, PA. (1980), p. 1777.

[6] G.R. Yoder, L.A. Cooley, T.W. Crooker: Metall. Mater. Trans. A. Vol. 9 (1978), p. 1413.

[7] G.R. Yoder, L.A. Cooley, T.W. Crooker: Trans. ASME.Vol.101 (1979), p. 86.

[8] K.S. Ravichandran: ASM Handbook. Fatigue and Fracture, American Society of Materials, Vol. 19 (1996), p. 159.

[9] MR. Bache, M. Tasleem: Fatigue life prediction techniques for notch geometries in titanium alloys. Int. J. Fatigue. Vol. 21(1999), p. 187.

[10] Evans WJ: Microstructure and the development of fatigue cracks at notches. Mater Science Eng. A. Vol. 263-2 (1999), p. 160.

[11] D. Eylon: Summary of the Available Information on the Processing of the Ti-6Al-4V HCF/LCF Program Plates, University of Dayton Report, University of Dayton, Dayton, OH, (1998). 
Manufacturing Science and Engineering I

doi:10.4028/www.scientific.net/AMR.97-101

A Comparison of Macroscopic Fracture Surface and Crack Growth Rate of Ti-6AI-4V doi:10.4028/www.scientific.net/AMR.97-101.687

\section{References}

[1] G.R. Yoder, D. Eylon: Metall. Mater. Trans. A. Vol. 10 (1979), p. 1808. doi:10.1007/BF02811724

[2] K.S. Chan, C.C. Wojcik, D.A. Koss: Metall. Mater. Trans. A. Vol. 12 (1981), p. 1899. doi:10.1007/BF02643801

[3] K.S. Ravichandran: Acta Metall. Mater. Vol. 39 (1991), p. 401. doi:10.1016/0956-7151(91)90319-V

[4] P. Lehr, in: H. Kimura, O. Izumi (Eds.), Titanium'80 Science and Technology, Metallurgical Society of AIME, Warrendale, PA. (1980), p. 1617.

[5] M. Peters, A. Gysler, G. Luetjering, in: H. Kimura, O. Izumi (Eds.), Titanium'80 Science and Technology, Metallurgical Society of AIME, Warrendale, PA. (1980), p. 1777.

[6] G.R. Yoder, L.A. Cooley, T.W. Crooker: Metall. Mater. Trans. A. Vol. 9 (1978), p. 1413. doi:10.1007/BF02661812

[7] G.R. Yoder, L.A. Cooley, T.W. Crooker: Trans. ASME.Vol.101 (1979), p. 86.

[8] K.S. Ravichandran: ASM Handbook. Fatigue and Fracture, American Society of Materials, Vol. 19 (1996), p. 159.

[9] MR. Bache, M. Tasleem: Fatigue life prediction techniques for notch geometries in titanium alloys. Int. J. Fatigue. Vol. 21(1999), p. 187.

doi:10.1016/S0142-1123(99)00071-7

[10] Evans WJ: Microstructure and the development of fatigue cracks at notches. Mater Science Eng. A. Vol. 263-2 (1999), p. 160.

[11] D. Eylon: Summary of the Available Information on the Processing of the Ti-6Al-4V HCF/LCF Program Plates, University of Dayton Report, University of Dayton, Dayton, $\mathrm{OH}$, (1998). 